\title{
How to design a registry for undiagnosed patients in the framework of rare disease diagnosis: suggestions on software, data set and coding system
}

\author{
Alexandra Berger ${ }^{1 *} \mathbb{D}$, Anne-Kathrin Rustemeier ${ }^{2}$, Jens Göbel ${ }^{3}$, Dennis Kadioglu ${ }^{3}$, Vanessa Britz ${ }^{1}$, \\ Katharina Schubert ${ }^{4}$, Klaus Mohnike $^{4}$, Holger Storf $^{3}$ and Thomas O. F. Wagner ${ }^{1}$
}

\begin{abstract}
Background: About 30 million people in the EU and USA, respectively, suffer from a rare disease. Driven by European legislative requirements, national strategies for the improvement of care in rare diseases are being developed. To improve timely and correct diagnosis for patients with rare diseases, the development of a registry for undiagnosed patients was recommended by the German National Action Plan. In this paper we focus on the question on how such a registry for undiagnosed patients can be built and which information it should contain.

Results: To develop a registry for undiagnosed patients, a software for data acquisition and storage, an appropriate data set and an applicable terminology/classification system for the data collected are needed. We have used the open-source software Open-Source Registry System for Rare Diseases (OSSE) to build the registry for undiagnosed patients. Our data set is based on the minimal data set for rare disease patient registries recommended by the European Rare Disease Registries Platform. We extended this Common Data Set to also include symptoms, clinical findings and other diagnoses. In order to ensure findability, comparability and statistical analysis, symptoms, clinical findings and diagnoses have to be encoded. We evaluated three medical ontologies (SNOMED CT, HPO and LOINC) for their usefulness. With exact matches of $98 \%$ of tested medical terms, a mean number of five deposited synonyms, SNOMED CT seemed to fit our needs best. HPO and LOINC provided $73 \%$ and $31 \%$ of exacts matches of clinical terms respectively. Allowing more generic codes for a defined symptom, with SNOMED CT 99\%, with HPO 89\% and with LOINC $39 \%$ of terms could be encoded.

Conclusions: With the use of the OSSE software and a data set, which, in addition to the Common Data Set, focuses on symptoms and clinical findings, a functioning and meaningful registry for undiagnosed patients can be implemented. The next step is the implementation of the registry in centres for rare diseases. With the help of medical informatics and big data analysis, case similarity analyses could be realized and aid as a decision-support tool enabling diagnosis of some undiagnosed patients.
\end{abstract}

Keywords: Registry, Undiagnosed patients, Rare diseases, HPO

\footnotetext{
*Correspondence: alexandra.berger@kgu.de

${ }^{1}$ Frankfurt Reference Centre for Rare Diseases, University Hospital

Frankfurt, Goethe University Frankfurt, Theodor-Stern-Kai 7, 60590 Frankfurt am Main, Germany

Full list of author information is available at the end of the article
}

\section{Background}

A rare disease is a health condition that affects a small number of people compared with other prevalent diseases in the general population. While there is no permits use, sharing, adaptation, distribution and reproduction in any medium or format, as long as you give appropriate credit to the original author(s) and the source, provide a link to the Creative Commons licence, and indicate if changes were made. The images or other third party material in this article are included in the article's Creative Commons licence, unless indicated otherwise in a credit line to the material. If material is not included in the article's Creative Commons licence and your intended use is not permitted by statutory regulation or exceeds the permitted use, you will need to obtain permission directly from the copyright holder. To view a copy of this licence, visit http://creativecommons.org/licenses/by/4.0/. The Creative Commons Public Domain Dedication waiver (http://creativeco mmons.org/publicdomain/zero/1.0/) applies to the data made available in this article, unless otherwise stated in a credit line to the data. 
universal definition of rare diseases, the concept of rare diseases in the current political and legislative framework is closely linked to a definition by point prevalence. Most jurisdictions include a prevalence threshold in at least one definition of rare diseases, whereas incidence as specification in a rare disease definition is seldomly used [1].

In the European Union (EU), a disease is considered to be rare, if it affects less than 5 of 10,000 people. In the United States of America (USA) a rare disease is defined as affecting less than 200,000 inhabitants, translating to a prevalence of about 8-9 out of 10,000 people [2]. About 30 million people in both the EU and the USA are suffering from a disease that is considered a rare disease $[3,4]$.

Orphanet is a 37-country network, aiming to increase knowledge of rare diseases. It was cofounded by the European Commission in 1997. As of 2020, classification and descriptions of 6172 rare diseases (by the European definition) are included in the Orphanet database; $71.9 \%$ being genetic and the onset of symptoms occurring during childhood in $69,9 \%$. About $85 \%$ of rare diseases are ultra-rare with a prevalence of less than 1 per 1,000,000 $[2,5]$.

Due to insufficient epidemiological data, lack of scientific publications and an absence of structured databases, the number of patients suffering from an uncharacterized disease is hard to estimate. In terms of uncharacterized genetic diseases, estimates state an unidentified underlying disease gene for at least 3,000 human Mendelian diseases, and the true number may be much higher [6].

Many rare diseases are severe chronic conditions with a complex clinical presentation and a negative impact on life expectancy and quality of life [7]. Prevention and cure as well as adequate therapies exist only for a minority of rare diseases [8]. Therefore, patients with rare diseases face a multitude of disease-related problems. Starting with delayed diagnosis, multiple doctor's visits before a diagnosis is made, misleading diagnosis, lack of comprehensive information provided at the time of diagnosis, insufficient coordination of care, inadequate transition from paediatric to adult care, and low or non-existent access to medication due to poor knowledge or lacking research and clinical trials. Patient organizations play a vital role in improving these circumstances $[9,10]$.

The diagnostic odyssey, that many patients affected by rare diseases experience, is often due to multiple causes: a non-specific clinical presentation involving multiple organ systems that seem to be unrelated, a general lack of awareness and physician training regarding rare diseases, missing standard diagnostic criteria, a limited number of specialists, uncoordinated patient journeys through the health-care system, that cause loss of information and increase the possibility of errors and sometimes limited access to diagnostic tools [11-13].

\section{The connection between undiagnosed and rare disease patients}

It is important to state, that rare diseases remain not always undiagnosed and undiagnosed diseases are not always hidden rare diseases. The undiagnosed patient can be affected by a rare disease, a more common disease that presents atypically, by multiple diseases occurring simultaneously, including psychosomatic disorders or by a completely new and uncharacterized disease. Both undiagnosed and rare disease patients require broad interdisciplinary evaluation, access to modern information resources and special diagnostic techniques including molecular genetics [14]. Therefore, the centres for rare diseases across Germany offer visiting hours for undiagnosed patients with or without a suspected rare disease.

In terms of the diagnostic process, a diagnosis can be delayed when the patient has not yet been referred to the appropriate expert. This can be caused by gatekeeping delays in primary care due to missing knowledge about rare diseases as well as systemic problems due to a lack of coordination, collaboration and adequate exchange of information between several healthcare providers [11, 15-17]. A complex diagnosis is defined by a nonconclusive phenotype and genomic profile, insufficient biomarkers, presentation of unspecific but common symptoms or the concurrent existence of more than one disease. In this case, the patient might require specific equipment and contact with a centre of expertise or a reference network. In case of a diagnostic impasse all available investigations have been carried out by experts and the patient and physicians may be facing a new, yet undescribed disorder $[3,11,16,17]$.

\section{Actions for rare diseases}

Initiated by patient organizations, rare diseases have gained attention in politics over the last decade. Driven by European legislative requirements, national strategies for the improvement of care in rare diseases had to be developed [18]. In Germany, the National Action Plan for People with Rare Diseases implemented 52 measures to improve health care for patients with rare diseases. Some examples are: Recommendations for the implementation of national centres of expertise, specific measures to accelerate time to diagnosis, research support, improvement of information management as well as suggestions on financing of these measures [19].

Concerning research, the development of a registry toolbox for creating individual disease-specific registries was requested. This registry toolbox should make use of an open-source software with a defined minimal data 
scheme and an emphasis on interoperability on a national and international level as well as metadata management [19]. This project was conducted collaboratively by the Institute of Medical Biometrics, Epidemiology and Informatics of the University Medical Centre of the Johannes Gutenberg University Mainz and the University Hospital Frankfurt in 2013 as part of the German National Action Plan and yielded the "Open Source Registry System for Seltene Erkrankungen (OSSE)". OSSE is an easily scalable and customizable framework for developing disease specific rare disease registries automatically connected to a meta data repository and fulfilling the FAIR data principles [20]: Findable: By describing metadata, people and computers can interact with the data to search for specific records. Accessible: Data is stored long-term, with defined license and access conditions, both at the level of metadata as well as the level of the instance data. Interoperable: Data sets can be combined with other data sets. Reusable: Data can be used for further research using computational methods. Further development of the OSSE registry framework is ongoing by the Medical Informatics Group (MIG) of the University Hospital Frankfurt [19, 21-23].

To improve timely and correct diagnosis for patients with rare diseases, the development of a 'registry for undiagnosed patients' was also recommended by the German National Action Plan, taking into account that a high percentage of these 'undiagnosed patients' eventually are diagnosed to have a rare disease [19].

Similar National strategies have been developed in most member states of the European Union as well as Norway, Switzerland and the UK [24] Some international examples are: The National Institutes of Health Undiagnosed Diseases Program, which started in 2008 [25]; the "Nan-Byo" (which translates as "difficult and illness"), which was established in 1972 in Japan and extended in 2015 as Japan's Initiative on Rare and Undiagnosed Diseases [26]; In February 2020, the Australian government announced to provide funding for activities to implement the National Strategic Action Plan for Rare Diseases, which was developed by Rare Voices Australia [27].

\section{Registries for rare diseases}

Registries in general and especially in the field of rare diseases can help to connect data from multiple health care providers $(\mathrm{HCP})$, thus enlarging the data base for research questions, including epidemiology of rare diseases. However, disease-specific ICD-10 codes are not available for most rare diseases and Orpha-codes, OMIM-codes or alpha-IDs are not used in routine clinical care. Therefore, prevalence calculated from diseasespecific registries have limited accuracy [28, 29]. And, of course, usually academia driven registries do not achieve sufficient representation of the whole disease population to allow calculation of prevalence.

Due to the fact that undiagnosed patients present with a wide variety of symptoms at different levels and specialities within the health care system, it is even more complicated to assess the number of undiagnosed patients.

Undiagnosed patients face specific problems caused by their lack of diagnosis. Such as long diagnostic odysseys and also a feeling of "not belonging anywhere" and self-doubt, which prevents access to self-help-groups and social support. Illustrating the feelings of suffering and loss, the inability to make plans, uncertainty, fear and rejection by clinicians and others, illness narratives of undiagnosed patients are from a chaotic type [30]. Therefore, it seems reasonable to create a registry addressing undiagnosed patients in order to create an opportunity to connect with others experiencing similar problems, shorten their path to diagnosis and by identifying chronic conditions at an earlier stage possibly producing savings to the health care system [31].

As most medical registries focus on one specific disease or group of diseases, they contain disease-specific and disease-relevant data. Patients, who are not yet diagnosed do not fit into these registry schemes. Therefore, in this paper we focus on the question on how such a registry for undiagnosed patients can be built and which information it should contain.

\section{Methods}

According to joint recommendations on how to improve the quality of rare disease registries, the first step is to classify the registry and to define its purpose and key stakeholders [32].

\section{Classification of the registry and definition of objectives}

The registry for undiagnosed patients is primarily a clinical registry focusing on the natural course of a group of diseases, namely ones, that are seemingly hard to recognize. It can be used to estimate the number of rare disease patients among the group of undiagnosed patients and, if operated nationwide, can aid to estimate the prevalence of undiagnosed patients, thus serving public health issues. It is a non-population-based registry, based on clinical centres for patients with rare (and undiagnosed) diseases. Inclusion criteria are: all patients presenting to a rare disease centre in search for a diagnosis who have given informed consent to participate in the registry, regardless of whether a rare disease is suspected or not. Exclusion criteria is a confirmed diagnosis of one or several diseases that explain all symptoms. The registry for undiagnosed patients is a mainly physician-driven registry, in which data is entered manually. 
The primary objective of our proposed registry for undiagnosed patients is to describe the population of patients, that remain undiagnosed and accompany them on the path to diagnosis while describing the natural course of their disease.

Secondary objectives are to facilitate research regarding rare diseases: As soon as a patient is diagnosed with a rare disease and agrees to data-sharing, the collected data set can be transferred to a disease-specific registry, if such a registry exists. This helps in gaining patients and data for disease-specific research questions as well as connecting different centres of expertise to work together more closely. Another objective is to help diagnosing patients earlier based on case-similarity analysis. By comparing the current and past clinical symptoms, objective findings and diagnoses of new patients with those who already received a diagnosis, possible similarities could mean, that the underlying diseases are the same. Additionally, very similar case histories of a number of undiagnosed patients could also help to identify patient cohorts for further targeted research.

Possible future objectives may also be the description of patient journeys and identifying structural problems in the health-care-system and to assess the quality of care of the particular centres of rare diseases, for example by including patient satisfaction reports as well as connecting undiagnosed patients and empowering them to advocate their needs in society. For these purposes though, new modules of data sets need to be developed.

With these objectives in mind, the key stakeholders of our proposed registry are the patients, the physicians treating them and the researchers in the centres for rare diseases. Despite the recommendation of Kodra et al. [32] to include all key stakeholders from the beginning in the process of developing a registry, we did not include patients in this process, as currently no patient-organization for undiagnosed patients exists in Germany.

To develop a registry for undiagnosed patients, a software for data acquisition and storage, an appropriate data set and an applicable terminology/classification system for the data used is needed [32].

\section{Registry software}

We have used the open-source software OSSE [21] as a framework for the registry for undiagnosed patients. This software enables users-even with limited IT-knowledge-to create registry data schemes for the individual purpose. The data items are specified as data elements in a metadata storage, where they can be retrieved to be reused as templates in future registries. This openly accessible metadata, and the possibility for researchers to get an impression of the data a registry collects, without forcing the registry to centrally disclose their data allow for a wide interoperability with other registries and research facilities. This in turn enables the researcher on the one hand to decide, which registries can provide appropriate data and on the other hand formulate a detailed inquiry for data using a so called OSSE decentral search inquiry [23].

Another strong point of the OSSE software is data protection. For pseudonymization, OSSE uses a broadly established open-source software, Mainzelliste, developed by the University Medical Centre of the Johannes Gutenberg University Mainz [33, 34]. OSSE also offers templates for patient information and declaration of consent. For further information on the software see https:// www.osse-register.de/en/ [21].

As mentioned above, OSSE complies with the FAIR data principles, ensures data protection, is easy to use by registry personnel, was developed by IT-specialists on our site and therefore fulfils all requirements of an ITsystem according to the recommendations of Kodra et al. [32].

\section{Data set and coding}

The basis of our work was the minimal data set for rare disease patient registries recommended for European cooperation Version 3.0 (see. Table 1). Version 3.0 differs only in minor aspects from Version 0.1 [35], which itself has been built based on the French minimal data set $R D$ MDS $v 1.08$ [36].

Two clinicians/researchers and two study nurses decided, how to expand this data set and which terminologies to use. They were advised by IT-personnel regarding further ideas and practicability in a course of repeated meetings over months. As mentioned above, no patients or patient representatives were included in this process.

As rare diseases are heterogenous and complex in their clinical presentation, we decided to extend the minimal data set by (subjective) symptoms and (objective) clinical findings together with the time of their first presentation as well as established or suspected diagnoses in each patient. This information can easily be obtained from prior medical records and the patient's history, which all patients have to provide when addressing rare disease centres to have their diagnostic halt overcome. Matching the information in prior medical files to the information, the patient gives directly (via interview or checklists) helps to validate the information and check for reliability. In order to ensure comparability and statistical evaluation, symptoms, clinical findings and diagnoses have to be encoded. Therefore, the registry forms have to be filled out at least partially by medical staff.

As the ICD-10 code does not have sufficient specificity and granularity for rare diseases, we included the Alpha 
Table 1 Data set for rare disease patient registries recommended for European Cooperation (Version 3.0), based on the French minimal data set RD MDS v1.08

\begin{tabular}{|c|c|c|c|c|c|c|}
\hline Item group & Item no & Item concept & Question & Content coding & $\begin{array}{l}\text { Data } \\
\text { collection } \\
\text { (one-time/ } \\
\text { repeatedly) }\end{array}$ & Comment \\
\hline 1. Pseudonym & 1.1 & Patient's Pseudonym (PID) & $\begin{array}{l}\text { Patient's Pseudonym (as } \\
\text { defined in the meta- } \\
\text { data-set) }\end{array}$ & String & One-time & \\
\hline \multirow[t]{2}{*}{ 2. Personal Information } & 2.4 & Patient's date of birth & $\begin{array}{l}\text { Patient's date of birth as } \\
\text { recorded on the birth } \\
\text { certificate }\end{array}$ & Date & One-time & \\
\hline & 2.5 & Gender & Patient's gender & $\begin{array}{l}\text { Female } \\
\text { Male } \\
\text { Undetermined } \\
\text { Unknown (for the foetus) }\end{array}$ & One-time & \\
\hline 3. Family Information & 3.1 & $\begin{array}{l}\text { Patient born from a } \\
\text { relationship between } \\
\text { related parties }\end{array}$ & $\begin{array}{l}\text { Is the patient born from } \\
\text { a relationship between } \\
\text { related parties }\end{array}$ & $\begin{array}{l}\text { Yes } \\
\text { No } \\
\text { Unknown }\end{array}$ & One-time & \\
\hline \multirow[t]{3}{*}{ 4. Vital status } & 4.1 & Patient's vital status & Is the patient still alive? & $\begin{array}{l}\text { Yes } \\
\text { No } \\
\text { Lost to follow-up } \\
\text { Discharged from registry }\end{array}$ & Repeatedly & $\begin{array}{l}\text { Update of the } \\
\text { data base at } \\
\text { least once } \\
\text { per year }\end{array}$ \\
\hline & 4.2 & Patient's date of death & Patient's date of death & Date & One-time & $\begin{array}{l}\text { Update of the } \\
\text { data base at } \\
\text { least once } \\
\text { per year }\end{array}$ \\
\hline & 4.3 & Death due to rare disease & $\begin{array}{l}\text { Is the death due to the } \\
\text { rare disease the patient } \\
\text { is suffering from? }\end{array}$ & $\begin{array}{l}\text { Yes } \\
\text { No } \\
\text { Unknown }\end{array}$ & & \\
\hline 5. Care pathway & 5.1 & $\begin{array}{l}\text { Patient's date of inclusion } \\
\text { in the registry }\end{array}$ & $\begin{array}{l}\text { Date at which the patient } \\
\text { was included in the } \\
\text { registry }\end{array}$ & Date & & \\
\hline \multirow[t]{2}{*}{ 6. Disease history } & 6.1 & Age at onset & $\begin{array}{l}\text { Age at which symptoms } \\
\text { first appeared }\end{array}$ & $\begin{array}{l}\text { Antenatal } \\
\text { At birth } \\
\text { XX year (s) and XX month } \\
(s) \\
\text { Undetermined }\end{array}$ & & \\
\hline & 6.2 & Age at diagnosis & $\begin{array}{l}\text { Age at which the diagno- } \\
\text { sis was made }\end{array}$ & $\begin{array}{l}\text { Antenatal } \\
\text { At birth } \\
\text { XX year (s) and XX month } \\
(s) \\
\text { Undetermined }\end{array}$ & & \\
\hline 7. Diagnosis & 7.2 & $\begin{array}{l}\text { Diagnosis of the rare } \\
\text { disease }\end{array}$ & $\begin{array}{l}\text { Diagnosis retained by the } \\
\text { RD center }\end{array}$ & Alpha code & & \\
\hline \multirow[t]{4}{*}{ 8. Research } & 8.1 & $\begin{array}{l}\text { Agreement to be con- } \\
\text { tacted for a protocol }\end{array}$ & $\begin{array}{l}\text { Does the patient give per- } \\
\text { mission to be contacted } \\
\text { for a research protocol? }\end{array}$ & $\begin{array}{l}\text { Yes } \\
\text { No }\end{array}$ & & \\
\hline & 8.2 & $\begin{array}{l}\text { Patient non-opposition to } \\
\text { the reuse of data }\end{array}$ & $\begin{array}{l}\text { Does the patient give per- } \\
\text { mission for his/her data } \\
\text { to be reused for other } \\
\text { research purposes? }\end{array}$ & $\begin{array}{l}\text { Yes } \\
\text { No }\end{array}$ & & \\
\hline & 8.3 & $\begin{array}{l}\text { Patient having previously } \\
\text { given a biological sam- } \\
\text { ple for research }\end{array}$ & $\begin{array}{l}\text { Has the patient already } \\
\text { given a biological sam- } \\
\text { ple for research? }\end{array}$ & $\begin{array}{l}\text { Yes } \\
\text { No }\end{array}$ & & \\
\hline & 8.4 & $\begin{array}{l}\text { Patient having previ- } \\
\text { ously given a biological } \\
\text { sample for molecular } \\
\text { diagnosis }\end{array}$ & $\begin{array}{l}\text { Has the patient already } \\
\text { given a biological } \\
\text { sample for molecular } \\
\text { diagnosis? }\end{array}$ & $\begin{array}{l}\text { Yes } \\
\text { No }\end{array}$ & & \\
\hline
\end{tabular}


ID [37] and Orpha Code [38] to encode rare diseases in the registry for undiagnosed patients.

We evaluated three terminologies resp. ontologies (in the following coding systems), i.e. Systematized Nomenclature of Medicine-Clinical Terms (SNOMED CT) [39], Human Phenotype Ontology (HPO) [40] and Logical Observation Identifiers Names and Codes (LOINC) [41] with regard to usefulness and feasibility for a registry for undiagnosed patients.

The Frankfurt Reference Centre for Rare Diseases (FRZSE), among other activities, runs a students' clinic for patients without a diagnosis, where patient cases are discussed in interdisciplinary teams to eventually find a diagnosis.

We used 10 random patient files from this students' clinic to evaluate the developed data set and to compare the 3 different coding systems. All identifying data of the files were removed, thus ensuring data protection by anonymization.

All symptoms, diagnoses and clinical findings mentioned in the medical records were extracted by one researcher and translated into English. Each symptom was extracted only once, regardless of how often it was mentioned in the file. Overall, 80 medical terms were extracted. These terms were entered in the browsers of each of the 3 coding systems. In some cases, more than one possible translation was entered into the browser to increase the chance of a match.

We evaluated the classification systems by numbers/ percentages of matches for the extracted medical terms. A term could be an exact match, a more general match, a match that is too specific, a match for which a quantitative figure is needed, or no match. This decision was made by the same researcher, who extracted the medical terms from the files.

\section{Results}

\section{Evaluation of coding systems}

With SNOMED CT, $98 \%$ of the 80 medical terms could be coded correctly. For one term, increase in waist circumference, an exact quantitative information is mandatory. Elevated gamma-glutamyl transferase levels could not be coded with SNOMED CT. For every medical term that could be coded correctly a mean number of 5 synonyms (range 2-15) was provided by SNOMED CT.

HPO provided exact matches for $73 \%$ of the terms. More general codes are available for $16 \%$ and codes that were too specific for $3 \%$ of the terms. $9 \%$ of the medical terms could not be coded. Only about 2 synonyms for each term are available so that further synonyms had to be entered manually to increase finding matches.

Only $31 \%$ of medical terms were coded correctly by the LOINC nomenclature. Generic codes are available for
$8 \%$, too specific ones for $33 \%$ of the terms. $8 \%$ of the medical terms could only be coded with an exact quantitative measurement. $21 \%$ of medical terms could not be coded at all. Therefore, symptoms and clinical findings cannot be coded sufficiently with LOINC. Lab values can only be represented with their exact value. Basic changes in lab values, for example hyponatraemia, cannot be described with LOINC. Medical terms and their synonyms had to be entered manually in most instances because LOINC only provides a mean of one synonym per term.

Under the assumption that also more generic coding terms are acceptable, $99 \%$ of medical terms are matched with SNOMED CT, $89 \%$ with HPO and 39\% with LOINC (see Fig. 1).

\section{Data set}

The development of the data set for the undiagnosed patients' registry was based on the minimal data set for rare disease patient registries recommended for European cooperation Version 3.0. [35] (see Table 1) This data set had been developed for the EUCERD-Action of the European Commission and has been the basis for the Set of Common Data Elements for Rare Diseases Registration, which was released by the EU Rare Disease platform with only some minor changes [42].

We extended the minimal data set by symptoms, clinical findings and prior diagnoses and generated two forms: a basic form, which is filled out initially when a patient is included in the registry and an episodic or longitudinal form, which can be filled out several times. (see Table 2). The basic form can only be altered by an administrator once the data set has been saved. The episodic form functions as a follow-up tool. The forms have to be filled out by personnel of the rare disease centre, for example study nurses or clinicians/researchers and may be included into the patients' medical files.

\section{The basic form}

Personal information such as name, surname, date of birth and current address, more precisely the postal code, is used to create the personal ID (pseudonym) with the Mainzelliste.

Gender of the patient is documented.

As over $70 \%$ of rare diseases have a genetic origin, we ask for the patient's parents' consanguinity in the family information.

We ask for vital status upon inclusion in the registry. If the patient has already died, the date of death is to be entered, too. Date of inclusion into the registry is reported.

For the disease history, we ask for the time when the first symptoms were noticed. 


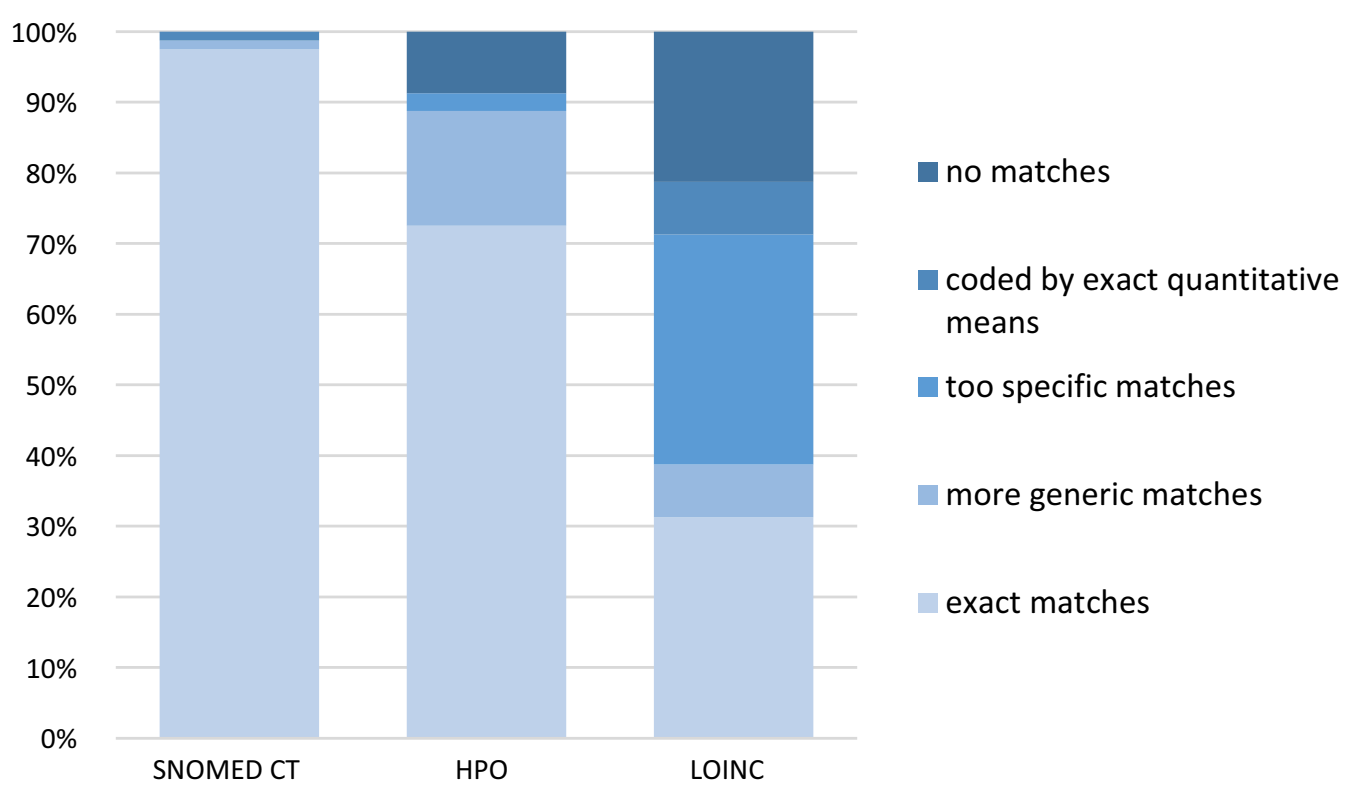

Fig. 1 Evaluation of classification systems regarding matches for extracted medical terms

Previously diagnosed diseases are prompted. These diagnoses shall be coded with an international disease classification, preferably with the ICD-10. When a more specific code is needed, for example when a coexisting rare disease is to be coded, Alpha-ID or Orpha Code, can be used. Therefore, the type of code as well as its description is to be entered as well. A statement whether the diagnosis has been confirmed or is still being suspected is asked for.

Symptoms and clinical findings are to be entered together with the type of nomenclature with which they are coded and an exact description of the term in the coding system. Year and month of the symptoms' first appearance are to be entered as well as its impact on the patient's life.

\section{The episodic form}

Together with the basic form, the first longitudinal form has to be completed. When an episodic form is created, the data collection date has to be entered. Then vital status, date of death and if death was caused by a rare disease, if applicable, are to be filled out.

Newly developed symptoms and further diagnoses can be entered as well as those that were missed to be documented during the first data collection. The number of symptoms and diagnoses that can be entered is not limited.

If a causal diagnosis is found which potentially explains all symptoms, this information can be recorded as well. The diagnosis itself shall again be coded preferably using the ICD-10. Type and description of the code, status of diagnosis, year and month of diagnosis and whether the disease is a rare one shall be entered.

Lastly, information for research questions is to be entered. As these can change over time, only the latest episodic form is applicable. The questions concerning research are:

1. Has the patient given consent to be contacted for a study protocol?

2. Has the patient been informed concerning and not opposed to a future re-use of his/her de-identified data for other research purposes?

3. Has the patient already given a biological sample for research?

\section{Test version}

After determination of the data set and a coding system, the Medical Informatics Group Frankfurt installed a test version of the registry for undiagnosed patients. This test version was evaluated in a preliminary manner in terms of content and ease of use. Multiple users entered data of randomly selected anonymized health records of the students' clinic for patients without a diagnosis of the FRZSE repeatedly. Technical problems as well as issues concerning the content were listed and discussed. The data set and user interface were optimized according to the identified problems. As a result, a tested and proven to work version of the registry for undiagnosed patients has been set up for further testing and evaluation in clinical routine. 
Table 2 Suggested data set for a registry for undiagnosed patients

\begin{tabular}{|c|c|c|c|c|}
\hline Item group & Item No & Item concept & Concept description & Content coding \\
\hline \multirow[t]{6}{*}{ 1. Personal data/information } & 1.1 & Patient's first name & $\begin{array}{l}\text { Patient's first name as specified on the } \\
\text { birth certificate or identity card }\end{array}$ & \\
\hline & 1.2 & Patient's (married) last name & Patient's (married) last name & \\
\hline & 1.3 & Patient's birth name & Patient's birth name & \\
\hline & 1.4 & Patient's date of birth & $\begin{array}{l}\text { Patient's date of birth as recorded on } \\
\text { the birth certificate and whether } \\
\text { Information is recorded for a foetus }\end{array}$ & \\
\hline & 1.5 & City of residence & Patient's current city of residence & \\
\hline & 1.6 & Gender & Patient's gender & $\begin{array}{l}\text { Female } \\
\text { Male } \\
\text { Undetermined } \\
\text { Unknown (for the foetus) }\end{array}$ \\
\hline 2. Family information & 2.1 & $\begin{array}{l}\text { Patient born from a relationship } \\
\text { between related parties }\end{array}$ & $\begin{array}{l}\text { Is the patient born from a relationship } \\
\text { between related parties? }\end{array}$ & $\begin{array}{l}\text { Unknown } \\
\text { No, suspected } \\
\text { No, confirmed } \\
\text { Yes, suspected } \\
\text { Yes, confirmed }\end{array}$ \\
\hline \multirow[t]{2}{*}{ 3. Vital Status } & 3.1 & $\begin{array}{l}\text { Patient's vital status upon inclusion } \\
\text { into the registry }\end{array}$ & Is the patient still alive? & $\begin{array}{l}\text { Alive } \\
\text { Dead }\end{array}$ \\
\hline & 3.2 & Patient's date of death & Patient's date of death & \\
\hline 4. Care Pathway & 4.1 & $\begin{array}{l}\text { Patient's date of inclusion in the RD } \\
\text { centre }\end{array}$ & $\begin{array}{l}\text { Date at which the patient was } \\
\text { recorded in the RD centre. Please } \\
\text { enter the date when the patient } \\
\text { was included in the internal medical } \\
\text { information system }\end{array}$ & \\
\hline 5. Disease history & 5.1 & Point in time at onset & $\begin{array}{l}\text { When were the symptoms first } \\
\text { noticed? (Only fill date input fields if } \\
\text { "lifetime" was selected) }\end{array}$ & $\begin{array}{l}\text { Antenatal } \\
\text { At birth } \\
\text { Undetermined } \\
\text { lifetime } \\
\text { 'Year of first manifestation' } \\
\text { 'Month of first manifestation' } \\
\text { 'Day of first manifestation }\end{array}$ \\
\hline \multirow{4}{*}{$\begin{array}{l}\text { 6. Diagnosis upon inclusion } \\
\text { into the registry }\end{array}$} & 6.1 & Diagnosis code & Prior Diagnosis (Code) & \\
\hline & 6.2 & Type of code & $\begin{array}{l}\text { Specify which type of code is used- } \\
\text { use ICD-10 if possible- }\end{array}$ & $\begin{array}{l}\text { ICD-10 } \\
\text { Alpha-ID } \\
\text { Orphacode }\end{array}$ \\
\hline & 6.3 & Description of the chosen Code & $\begin{array}{l}\text { Description of the chosen code. Please } \\
\text { copy the EXACT text belonging to } \\
\text { the code. Do NOT enter free text }\end{array}$ & \\
\hline & 6.4 & Status of diagnosis & $\begin{array}{l}\text { Specify whether the diagnosis is } \\
\text { already confirmed or only suspected }\end{array}$ & $\begin{array}{l}\text { Unknown } \\
\text { Confirmed } \\
\text { Suspected }\end{array}$ \\
\hline
\end{tabular}


Table 2 (continued)

\begin{tabular}{|c|c|c|c|c|}
\hline Item group & Item No & Item concept & Concept description & Content coding \\
\hline \multirow[t]{6}{*}{ 7. Symptom history } & 7.1 & Diagnosis code (Symptom) & Diagnosis (code) of the symptom & \\
\hline & 7.2 & Type of code (Symptom) & $\begin{array}{l}\text { Specify which type of code is used- } \\
\text { use HPO if possible- }\end{array}$ & $\begin{array}{l}\text { HPO } \\
\text { SNOMED-CT }\end{array}$ \\
\hline & 7.3 & Symptom Ontology description & Description from the selected code & \\
\hline & 7.4 & Symptom priority & Symptom priority & $\begin{array}{l}\text { Unknown } \\
\text { High } \\
\text { Medium } \\
\text { Low }\end{array}$ \\
\hline & 7.5 & Year of first manifestation & Year of first manifestation & \\
\hline & 7.6 & Month of first manifestation & Month of first manifestation & $\begin{array}{l}\text { Unknown } \\
\text { January } \\
\text { February } \\
\text { March } \\
\text { April } \\
\text { May } \\
\text { June } \\
\text { July } \\
\text { August } \\
\text { September } \\
\text { October } \\
\text { November } \\
\text { December }\end{array}$ \\
\hline \multirow[t]{3}{*}{ E1. Vital Status } & E1.1 & Patient's vital status & Is the patient still alive & $\begin{array}{l}\text { Alive } \\
\text { Dead } \\
\text { Lost to follow up } \\
\text { Discharged from registry }\end{array}$ \\
\hline & E1.2 & Patient's date of death & Patient's date of death & \\
\hline & E1.3 & Death due to the rare disease & $\begin{array}{l}\text { Is the death due to the rare disease the } \\
\text { patient is suffering from? }\end{array}$ & $\begin{array}{l}\text { Yes } \\
\text { No } \\
\text { Unknown }\end{array}$ \\
\hline \multirow[t]{6}{*}{ E2. Further Symptoms } & & Diagnosis code (Symptom) & Diagnosis (code) of the symptom & \\
\hline & E2.1 & Type of code (Symptom) & $\begin{array}{l}\text { Specify which type of code is used- } \\
\text { use HPO if possible- }\end{array}$ & $\begin{array}{l}\text { HPO } \\
\text { SNOMED-CT }\end{array}$ \\
\hline & $\mathrm{E} 2.2$ & Symptom Ontology description & Description from the selected code & \\
\hline & $\mathrm{E} 2.3$ & Symptom priority & Symptom priority & $\begin{array}{l}\text { Unknown } \\
\text { High } \\
\text { Medium } \\
\text { Low }\end{array}$ \\
\hline & E2.4 & Year of first manifestation & Year of first manifestation & \\
\hline & $\mathrm{E} 2.5$ & Month of first manifestation & Month of first manifestation & $\begin{array}{l}\text { Unknown } \\
\text { January, } \\
\text { February } \\
\text { March, } \\
\text { April } \\
\text { May, } \\
\text { June } \\
\text { July, } \\
\text { August } \\
\text { September } \\
\text { October } \\
\text { November } \\
\text { December }\end{array}$ \\
\hline
\end{tabular}


Table 2 (continued)

\begin{tabular}{|c|c|c|c|c|}
\hline Item group & Item No & Item concept & Concept description & Content coding \\
\hline \multirow[t]{4}{*}{ E3. Further Diagnosis } & E3.1 & Diagnosis code & Prior Diagnosis (Code) & \\
\hline & E3.2 & Type of code & $\begin{array}{l}\text { Specify which type of code is used- } \\
\text { use ICD-10 if possible- }\end{array}$ & $\begin{array}{l}\text { ICD-10 } \\
\text { Alpha-ID } \\
\text { Orphacode }\end{array}$ \\
\hline & E3.3 & Description of the chosen Code & $\begin{array}{l}\text { Description of the chosen code. Please } \\
\text { copy the EXACT text belonging to } \\
\text { the code. Do NOT enter free text }\end{array}$ & \\
\hline & E3.4 & Status of diagnosis & $\begin{array}{l}\text { Specify whether the diagnosis is } \\
\text { already confirmed or only suspected }\end{array}$ & $\begin{array}{l}\text { Unknown } \\
\text { Confirmed } \\
\text { Suspected }\end{array}$ \\
\hline \multirow[t]{7}{*}{ E4. Causal Diagnosis (final) } & E4.1 & Diagnosis code & Diagnosis (Code) & \\
\hline & $\mathrm{E} 4.2$ & Type of code & $\begin{array}{l}\text { Specify which type of code is used- } \\
\text { use ICD-10 if possible- }\end{array}$ & $\begin{array}{l}\text { ICD-10 } \\
\text { Alpha-ID } \\
\text { Orphacode }\end{array}$ \\
\hline & $\mathrm{E} 4.3$ & Description of the chosen Code & $\begin{array}{l}\text { Description of the chosen code. Please } \\
\text { copy the EXACT text belonging to } \\
\text { the code. Do NOT enter free text }\end{array}$ & \\
\hline & $\mathrm{E} 4.4$ & Status of diagnosis & $\begin{array}{l}\text { Specify whether the diagnosis is } \\
\text { already confirmed or only suspected }\end{array}$ & $\begin{array}{l}\text { Unknown } \\
\text { Confirmed } \\
\text { Suspected }\end{array}$ \\
\hline & $\mathrm{E} 4.5$ & Rare Disease & $\begin{array}{l}\text { Is the newly found diagnosis a rare } \\
\text { disease? }\end{array}$ & (Click box) \\
\hline & E4.6 & Year of diagnosis & Year of diagnosis & \\
\hline & $\mathrm{E} 4.7$ & Month of diagnosis & Month of diagnosis & $\begin{array}{l}\text { Unknown } \\
\text { January } \\
\text { February } \\
\text { March } \\
\text { April } \\
\text { May } \\
\text { June } \\
\text { July } \\
\text { August } \\
\text { September } \\
\text { October } \\
\text { November } \\
\text { December }\end{array}$ \\
\hline \multirow[t]{3}{*}{ E5. Research } & E5.1 & $\begin{array}{l}\text { Agreement to be contacted for a } \\
\text { protocol }\end{array}$ & $\begin{array}{l}\text { Does the patient give permission to be } \\
\text { contacted for a research protocol? }\end{array}$ & $\begin{array}{l}\text { Yes } \\
\text { No } \\
\text { Unknown }\end{array}$ \\
\hline & E5.2 & $\begin{array}{l}\text { Patient non-opposition to the reuse } \\
\text { of data }\end{array}$ & $\begin{array}{l}\text { Is the patient non-opposite to the } \\
\text { reuse of data? }\end{array}$ & $\begin{array}{l}\text { Yes } \\
\text { No } \\
\text { Unknown }\end{array}$ \\
\hline & E5.3 & $\begin{array}{l}\text { Patient having previously given a } \\
\text { biological sample for research }\end{array}$ & $\begin{array}{l}\text { Has the patient already given a biologi- } \\
\text { cal sample for research? }\end{array}$ & $\begin{array}{l}\text { Yes } \\
\text { No } \\
\text { Unknown }\end{array}$ \\
\hline
\end{tabular}

\section{Discussion}

To ensure comparability of 'undiagnosed patients' registry entries, findings and symptoms have to be encoded. We evaluated three medical coding systems (SNOMED $\mathrm{CT}, \mathrm{HPO}$ and LOINC) for their usefulness and feasibility. For our purposes, finding exact matches for symptoms described by patients and clinical findings as mentioned in the health record is necessary.
With exact matches of $98 \%$ of tested medical terms, a mean number of five deposited synonyms, SNOMED CT seemed to fit our needs best.

HPO and LOINC provided $73 \%$ and $31 \%$ of exact matches of clinical terms respectively. Bringing in more generic terms for a defined symptom, with SNOMED CT $99 \%$, with HPO $89 \%$ and with LOINC 39\% of terms could be coded. One has to consider, though, that by using 
more generic or too specific terms the precise meaning of a symptom can be lost. For example: Raynaud's phenomenon could be coded exactly with the SNOMED CT code "SCTID 266261006". HPO provides only the more general codes for "cyanosis" (HPO-Code 0000961) or "abnormality of blood circulation" (HPO-Code 0011028) whereas the LOINC-code 67732-8 encodes only a very specific clinical situation, namely white finger syndrome or Raynaud's syndrome caused by excessive vibration from pneumatic hammers or drills.

With a hit ratio of $31 \%$, LOINC was not suitable for sufficiently coding symptoms and clinical findings in our test-cases.

One could argue that the evaluation of only 10 patient files for the comparison of the three coding systems, is not enough. The focus of our study was, however, to estimate the usefulness and feasibility of each nomenclature for the purpose of the registry. So, even when working with only a few cases, the strengths and limitations of each nomenclature according to the needs of the registry, appear quite clear.

Both the extraction of medical terms, their translation into English as well as deciding whether the term could be matched exactly or not with one of the coding systems was made by only one person. This makes our evaluation of the three coding systems potentially subject to errors. It would have been better, to have two researchers extract the terms and define the exactness of a match independently of each other. Possibly involving a third person who decides, when the results of the two researchers vary. We don't assume, though, that many errors were made extracting the medical terms as working out the guiding symptoms is a daily task for clinicians. Deciding, whether a match is an exact one, does not seem difficult as it either is an exact match or not. Therefore, we think, that having assigned more researchers to these tasks would not have changed the results of our evaluation significantly.

The HPO ontology is extended continuously [43]. We expect the fraction of adequate hits of HPO to improve significantly over time. HPO is widely used for deep phenotyping in the field of rare diseases. The phenotype profile can be compared with computational disease profiles in the HPO database with the aim of identifying genetic diseases with comparable phenotypic profiles. Also, HPO provides for interoperability with other ontologies and it plays a key role with the Exomizer tool, which identifies potential disease-causing variants from whole-exome or whole-genome sequencing data $[43,44]$.

Taking into account HPO's acceptable match rate of medical terms, the fact that it is available free of charge and especially its wide application and interoperability in the field of rare diseases, we think that HPO is the ontology of choice for an undiagnosed patients' registry.

The European Common Data Set for Rare Disease Registration also recommends the phenotype of patients to be recorded with HPO [42]. In cases where a symptom cannot be coded adequately with HPO, a request can be sent to the developers of HPO to ask for the definition and addition of a new more suitable code to the HPO ontology for future use.

Although SNOMED CT proved to be the best fit for our needs, one limitation is the requirement of a national license, which is available in Germany only since the beginning of 2020 and for now only in the context of the Medical Informatics Initiative in Germany [45]. Furthermore, the current national license and use of SNOMED $\mathrm{CT}$ is still undergoing evaluation. However, as the German policy clearly strives for a permanent adoption, we take SNOMED CT into account in the context of future operations and further development of our registry.

Since OSSE as a registry toolkit allows for an uncomplicated modification of the registry's forms and data elements, one of the first adjustments should be the inclusion of date of first contact with a specialized centre and a genetic diagnosis, coded by the international classification of mutations (HGVS) as suggested by the European Common Data Set for Rare disease registries. The inclusion of the patient's disability profile according to the international classification of functioning and disability does not seem practical to us, as it is far too comprehensive to be implemented into the routine service of centres for rare diseases [42].

As OSSE is an open-source software, further developments and adjustments could be performed to meet specific needs of the distinctive nature of a registry for undiagnosed patients. Such changes could for example include statistics that would be calculated dynamically as the data base grows to show progress in the process of diagnosing patients or other key values.

Recurring issues in the field of registries in general and especially in the field of rare diseases are sustainability and ethical as well as legal concerns, particularly data protection regulations.

After initial funding of the software development by the European Commission, users of the OSSE software have to manage sustainable funding of such registries on a national level. In some European countries such funding is available within the framework of the respective national plan for rare diseases. In Germany, another means of funding can be through additional surcharges for particular tasks of specialized care centres. A resolution of the Gemeinsamer Bundesausschuss (G-BA) as of November 20th, 2020 has defined the implementation and/or conduction and evaluation of a registry for rare 
diseases as one of several specialized tasks of centres for rare diseases [46, 47].

Another critical point is the establishment of our proposed registry in different centres for rare diseases across Germany and possibly Europe. Every research site has to examine itself, whether a project like this registry meets all the ethical and legal requirements. A crucial point is data ownership and data sharing. A request to share identifiable patients' data, even in the framework of a joint research project, leads to inquiries at the legal department and the data protection office in most cases. Therefore, we favour a decentral approach of multiple registries at different sites using the same metadata and data sets, that enables joint data evaluation using only de-identified data. The data collected by each registry remains in the custodianship of each site. Another consideration is the ongoing activity to establish registries for undiagnosed patients in several rare disease centres. Most likely, such separate registries may have their own primary objective. As the parallel existence of multiple registries usually leads to expensive efforts for the necessary data integration, we think it is crucial, that such registries are respecting existing standards of data schemes and support data integration. Our proposed registry, set up based with the OSSE toolbox, could serve as a blueprint and joint minimal data set for such registries. Each site is free to enlarge its own registry application with additional data elements, e.g., such as indicators regarding patient journeys, patient satisfaction or quality of life. It is important to involve patient organizations, who are one of the key stakeholders, in developing these to make sure, that the data elements are meaningful from their position, too. Enabling other centres to use these extensions can increase the data base for collaborative data evaluation. Therefore, it would be very helpful, if every registry site shared their metadata in publicly accessible repositories, which can easily be accomplished with the OSSE metadata repository. Furthermore, to be found by the community or whoever is interested, every registry should be enlisted in a registry of registries, i.e. the European Rare Disease Registry Infrastructure Directory of Registries [48].

\section{Conclusions}

With the use of the OSSE software and a data set which focuses on symptoms and clinical findings, a functioning and meaningful registry for undiagnosed patients can be implemented. The next step is the utilization of the registry in centres for rare diseases. The FRZSE is currently creating a retrospective registry containing the data of all its previous patients. This project will show, among other things, if the design of the registry suggested by us meets the needs in clinical routine and can be applied to a large number of patients. After evaluation and possible adjustments, we also plan to implement a multi-centre decentral prospective registry.

\begin{abstract}
Acknowledgements
Not applicable.

Authors' contributions

$A B$ wrote this manuscript based on ARs thesis draft; she put the work into perspective regarding recent literature and research activities. AR extracted the medical terms from the patients'files, encoded them and analysed the match rates for the 3 nomenclatures. Also, she wrote her doctoral thesis on this topic. JB, DK and HS set up the registry with the OSSE-Software and further adapted the software to our needs and together with VB, KS and KM discussed and revised the manuscript. TOFW initiated the research project, contributed substantially to the conception of the work and supervised all other contributors. $A B$ is a general practitioner currently working in the Frankfurt Reference Centre for Rare Diseases. Just recently, she was appointed a board member of the AG ZSE, a collaboration of Rare Disease Centres throughout Germany. All authors read and approved the final manuscript.
\end{abstract}

\section{Funding}

Open Access funding enabled and organized by Projekt DEAL.

\section{Availability of data and materials}

The datasets used during the current study are available from the corresponding author on reasonable request.

\section{Declarations}

Ethics approval and consent

This study was approved by the ethics committee of the Universitätsklinikum Frankfurt. Number: 20-26, Date: May 5th, 2020.

\section{Consent for publication}

Not applicable.

\section{Competing interests}

The authors state that they have no competing interests.

\section{Author details}

${ }^{1}$ Frankfurt Reference Centre for Rare Diseases, University Hospital Frankfurt, Goethe University Frankfurt, Theodor-Stern-Kai 7, 60590 Frankfurt am Main, Germany. ${ }^{2}$ Medical Clinic II, University Hospital Gießen and Marburg, Klinikstraße 33, 35392 Gießen, Germany. ${ }^{3}$ Medical Informatics Group Frankfurt, University Hospital Frankfurt, Goethe University Frankfurt, Theodor-Stern-Kai 7, 60590 Frankfurt am Main, Germany. ${ }^{4}$ Central-German Network for rare diseases, University Hospital Magdeburg A.Ö.R, Leipziger Straße 44, 39120 Magdeburg, Germany.

Received: 1 December 2020 Accepted: 20 April 2021

Published online: 01 May 2021

\section{References}

1. Richter T, Nestler-Parr S, Babela R, Khan ZM, Tesoro T, Molsen E, et al. Rare disease terminology and definitions-a systematic global review: report of the ISPOR Rare Disease Special Interest Group. Value Health. 2015;18(6):906-14.

2. Nguengang Wakap S, Lambert DM, Olry A, Rodwell C, Gueydan C, Lanneau $V$, et al. Estimating cumulative point prevalence of rare diseases: analysis of the Orphanet database. Eur J Hum Genet. 2019;28(2):165-73. 
3. Griggs RC, Batshaw M, Dunkle M, Gopal-Srivastava R, Kaye E, Krischer J, et al. Clinical research for rare disease: opportunities, challenges, and solutions. Mol Genet Metab. 2009;96(1):20-6.

4. Union RdE. Empfehlung des Rates vom 8. Juni 2009 für eine Maßnahme im Bereich seltener Krankheiten Amtsblatt der Europäischen Union Nr. C 1512009 [3. Juli 2009]. https://eur-lex.europa.eu/LexUriServ/LexUriServ. do?uri=CELEX:32009H0703\%2802\%29:DE:HTML.

5. Procedural document on the Orphanet nomenclature and classification of rare diseases, Orphanet, March 2020, Number 02 2020. https://www. orpha.net/orphacom/cahiers/docs/GB/eproc_disease_inventory_R1_ Nom_Dis_EP_04.pdf.

6. Krawitz P, Buske O, Zhu N, Brudno M, Robinson PN. The genomic birthday paradox: how much is enough? Hum Mutat. 2015;36(10):989-97.

7. Frank M, Eidt-Koch D, Aumann I, Reimann A, Wagner TO, von der Schulenburg JMG. [Measures to improve the health situation of patients with rare diseases in Germany. A comparison with the National Action Plan]. Bundesgesundheitsblatt Gesundheitsforschung Gesundheitsschutz. 2014;57(10):1216-23.

8. Taruscio D, Gentile AE, Evangelista T, Frazzica RG, Bushby K, Montserrat AM. Centres of Expertise and European Reference Networks: key issues in the field of rare diseases. The EUCERD Recommendations. Blood Transfus. 2014;12 Suppl 3(Suppl 3):s621-5.

9. Molster C, Urwin D, Di Pietro L, Fookes M, Petrie D, Van Der Laan S, et al. Survey of healthcare experiences of Australian adults living with rare diseases. Orphanet J Rare Dis. 2016;11(1):30.

10. Limb L, Nutt S, Sen A. Experiences of rare diseases: an insight from patients and families. Rare Diseases UK; 2010.

11. Hartley T, Lemire G, Kernohan KD, Howley HE, Adams DR, Boycott KM. New diagnostic approaches for undiagnosed rare genetic diseases. Annu Rev Genom Hum Genet. 2020;21:351-72.

12. Johnson JK, Farnan JM, Barach P, Hesselink G, Wollersheim H, Pijnenborg $L$, et al. Searching for the missing pieces between the hospital and primary care: mapping the patient process during care transitions. BMJ Qual Saf. 2012;21(Suppl 1):i97-105.

13. Schieppati A, Henter Jl, Daina E, Aperia A. Why rare diseases are an important medical and social issue. Lancet. 2008;371(9629):2039-41.

14. Mueller T, Jerrentrup A, Bauer MJ, Fritsch HW, Schaefer JR. Characteristics of patients contacting a center for undiagnosed and rare diseases. Orphanet J Rare Dis. 2016;11(1):81

15. de Vries E, Fransen L, van den Aker M, Meijboom BR. Preventing gatekeeping delays in the diagnosis of rare diseases. Br J Gen Pract. 2018;68(668):145-6.

16. Undiagnosed rare diseases Orphanet Journal of Rare Diseases. https:// www.biomedcentral.com/collections/undiagnosedrare.

17. Splinter K, Adams DR, Bacino CA, Bellen HJ, Bernstein JA, Cheatle-Jarvela AM, et al. Effect of genetic diagnosis on patients with previously undiagnosed disease. N Engl J Med. 2018;379(22):2131-9.

18. COUNCIL RECOMMENDATION of 8 June 2009 on an action in the field of rare diseases Official Journal of the European Union C1512009. https:// eur-lex.europa.eu/LexUriServ/LexUriServ.do?uri=OJ:C:2009:151:0007: 0010:EN:PDF.

19. Nationaler Aktionsplan für Menschen mit Seltenen Erkrankungen andlungsfelder, Empfehlungen und Maßnahmenvorschläge:: BMG, BMBF, ACHSE e.V. 2019. https://www.namse.de/fileadmin/user_upload/downl oad.

20. Wilkinson MD, Dumontier M, Jan Aalbersberg I, Appleton G, Axton M, Baak A, et al. Addendum: the FAIR Guiding Principles for scientific data management and stewardship. Sci Data. 2019;6(1):6.

21. Mainz U. OSSE - Open Source Registry System for Rare Diseases in the EU. osse-register.de.

22. Schaaf J, Kadioglu D, Goebel J, Behrendt CA, Roos M, van Enckevort D, et al. OSSE goes FAIR - implementation of the FAIR data principles for an open-source registry for rare diseases. Stud Health Technol Inform. 2018;253:209-13.

23. Storf H, Schaaf J, Kadioglu D, Gobel J, Wagner TOF, Uckert F. Registries for rare diseases: OSSE-an open-source framework for technical implementation. Bundesgesundheitsblatt Gesundheitsforschung Gesundheitsschutz. 2017;60(5):523-31.
24. EUROPLAN - European Project for Rare Diseases National Plans Development. http://www.europlanproject.eu/NationalPlans?idMap=1.

25. Gahl WA, Mulvihill JJ, Toro C, Markello TC, Wise AL, Ramoni RB, et al. The $\mathrm{NIH}$ undiagnosed diseases program and network: applications to modern medicine. Mol Genet Metab. 2016;117(4):393-400.

26. Adachi T, Imanishi N, Ogawa Y, Furusawa Y, Izumida Y, Izumi Y, et al. Survey on patients with undiagnosed diseases in Japan: potential patient numbers benefiting from Japan's initiative on rare and undiagnosed diseases (IRUD). Orphanet J Rare Dis. 2018;13(1):208.

27. MP THGH, Health Mf. First National Action Plan for rare diseases 26 Feb 2020. https://www.health.gov.au/ministers/the-hon-greg-hunt-mp/ media/first-national-action-plan-for-rare-diseases.

28. Communication From The Commission to The European Parliament, The Council, The European Economic and Social Committee and the Committee Of The Regions on Rare Diseases: Europe's challenges. https://ec. europa.eu/health/ph threats/non_com/docs/rare com en.pdf.

29. Marx MM, Dulas FM, Schumacher KM. Verbesserung der Sichtbarkeit seltener Erkrankungen in Gesundheitssystemen durch spezifische Routinekodierung. Bundesgesundheitsblatt - Gesundheitsforschung Gesundheitsschutz. 2017;60(5):532-6.

30. Spillmann RC, McConkie-Rosell A, Pena L, Jiang YH, Schoch K, Walley $\mathrm{N}$, et al. A window into living with an undiagnosed disease: illness narratives from the undiagnosed diseases network. Orphanet J Rare Dis. 2017:12(1):71.

31. Deyo D, Hemingway J, Hughes DR. Identifying patients with undiagnosed chronic conditions: an examination of patient costs before chronic disease diagnosis. J Am Coll Radiol. 2015;12(12 Pt B):1388-94.

32. Kodra Y, Weinbach J, Posada-De-La-Paz M, Coi A, Lemonnier S, Van Enckevort $\mathrm{D}$, et al. Recommendations for improving the quality of rare disease registries. Int J Environ Res Public Health. 2018;15(8):1644.

33. Mainzelliste as an Open Source Service [Mainzelliste]. https://www.unime dizin-mainz.de/imbei/informatik/ag-verbundforschung/mainzelliste. html?L=1.

34. Lablans M, Borg A, Ückert F. A RESTful interface to pseudonymization services in modern web applications. BMC Med Inform Decis Mak. 2015;15(1):2.

35. ACTION EJ. Minimum Data Set For Rare Disease Registries 2015. http:// www.eucerd.eu/wp-content/uploads//2015/03/WP8_Registries_MDS. pdf.

36. Choquet R, Maaroufi M, De Carrara A, Messiaen C, Luigi E, Landais P. A methodology for a minimum data set for rare diseases to support national centers of excellence for healthcare and research. J Am Med Inform Assoc. 2015;22(1):76-85.

37. Thun S, Jakob R, Schlutius S, Dauben HP. Alpha-ID - Anwendungsbereiche und internationale Verwendung. 50 Jahrestagung der Deutschen Gesellschaft für Medizinische Informatik, Biometrie und Epidemiologie (gmds), 12 Jahrestagung der Deutschen Arbeitsgemeinschaft für Epidemiologie; 8 Sept 2005; Freiburg im Breisgau,.

38. Orphanet. Orphadata - Rare Diseases and Classifications [updated 01 Nov 2020]. http://www.orphadata.org/cgi-bin/rare_free.html.

39. Wang $Y$, Halper M, Wei D, Gu H, Perl Y, Xu J, et al. Auditing complex concepts of SNOMED using a refined hierarchical abstraction network. J Biomed Inform. 2012;45(1):1-14.

40. Robinson PN, Köhler S, Bauer S, Seelow D, Horn D, Mundlos S. The human phenotype ontology: a tool for annotating and analyzing human hereditary disease. Am J Human Genet. 2008;83(5):610-5.

41. LOINC from Regenstrief: a universal code system for tests, measurements, and observations. https://loinc.org/.

42. Set of Common Data Elements for Rare Diseases Registration: European Platform on Rare Disease Registration (EU RD Platform). https://eu-rd-platf orm.jrc.ec.europa.eu/sites/default/files/CDS/EU_RD_Platform_CDS_Final. pdf.

43. Köhler S, Carmody L, Vasilevsky N, Jacobsen JOB, Danis D, Gourdine JP, et al. Expansion of the Human Phenotype Ontology (HPO) knowledge base and resources. Nucleic Acids Res. 2019;47(D1):D1018-27.

44. Köhler S, Øien NC, Buske OJ, Groza T, Jacobsen JOB, McNamara C, et al. Encoding clinical data with the human phenotype ontology for computational differential diagnostics. Curr Protoc Hum Genet. 2019;103(1):e92. 
45. Pressemitteilung 033/2020: Digitalisierung: Medizinische Daten sprechen zukünftig eine gemeinsame Sprache [press release]. 2020.

46. Bundesausschuss G. Bekanntmachung eines Beschlusses des Gemeinsamen Bundesausschusses über eine Änderung der Zentrums-Regelungen: Änderungen in den $\S \S 3$ und 5 sowie in den Anlagen 6, 7, 8 und 9. In: Gesundheit Bf, editor. BAnz AT 17 Dec 2020 B82020.

47. Bundesausschuss G. Bekanntmachung eines Beschlusses des Gemeinsamen Bundesausschusses über die Erstfassung der Regelungen zur Konkretisierung der besonderen Aufgaben von Zentren und Schwerpunkten gemäß § 136c Absatz 5 des Fünften Buches Sozialgesetzbuch
(SGB V) (Zentrums-Regelungen). In: Gesundheit BF, editor. BAnz AT 12032020 B22020.

48. European Rare Disease Registry Infrastructure (ERDRI). https://eu-rd-platf orm.jrc.ec.europa.eu/erdri-description_en\#inline-nav-1.

\section{Publisher's Note}

Springer Nature remains neutral with regard to jurisdictional claims in published maps and institutional affiliations.
Ready to submit your research? Choose BMC and benefit from:

- fast, convenient online submission

- thorough peer review by experienced researchers in your field

- rapid publication on acceptance

- support for research data, including large and complex data types

- gold Open Access which fosters wider collaboration and increased citations

- maximum visibility for your research: over $100 \mathrm{M}$ website views per year

At BMC, research is always in progress.

Learn more biomedcentral.com/submissions 